Article, Review, Communication (Type of Paper)

\title{
Requalification European projects of "Nearly Zero Energy Building" for smart district and cities
}

\author{
Renata Morbiducci ${ }^{1}$ * \\ ${ }^{1}$ Department of Sciences for Architecture (DSA), Polytechnic School, University of Genova / \\ Stradone S. Agostino, 3716123 Genova Italy
}

E-Mails: renata.morbiducci@unige.it

* Tel.: +39 0102095760; Fax: +39 0102095905

Received: 17 September 2013 / Accepted: 28 October 2013 / Published: 01 November 2013

\begin{abstract}
The author present several results of some different European Project about the call "Smart Cities and Communities in Europe". The main objective of these projects is to develop a replicable strategy for the design, construction and management of entire residential neighborhoods with "almost zero" consumption. The experience, both in the competition participation and in the course of the phases of the project, it is particularly significant, especially for the synergy that has necessarily developed at international level, including Municipality, researchers, industries, non-profit companies and finance companies. Regarding the role of the University is evident the contribution in terms of knowledge and strength of cohesion between the different actors involved.
\end{abstract}

Keywords: European project, district energy requalification, energetic performances, sustainable evaluations by several kinds of analyses.

\section{Introduction}

The equipment Italian social housing is far lower than the European canons: only 4\%, compared to $20 \%$ of the overall EU average. After the Second World War the rapid population growth and economic development have resulted in the need to provide low-cost housing by stimulating the 
intensive construction of social housing. In those years energy efficiency, durability and sustainability were not important issues, resulting in any case irrelevant in comparison to the quantitative demand of residence. The trend of growth in residential volumes peaked in the '70s, during which there has been a consistence building stock. Today it strongly degraded and therefore it needs a technological and functional refurbishment. Almost always the need for technological upgrading is accompanied by the need to regenerate the social framework for which the low quality level of construction hasn't certainly helped to find opportunities for social cohesion and own growth (2).

From several years the EU member states have begun to promote a process of technological renovation of these urban realities considering the possibility to improve the internal comfort and the energy efficiency, in other worlds to improve the sustainable requalification of entire districts. Each member country has a different existing building stock, with different problems and thus, in the last decade, everyone tried to intervene with specific logic and approaches, but starting from a common observation: these buildings are more vulnerable than other because they are inefficient in several performance aspects. They could consequently deteriorate more rapidly than others. Thus the retrofitting actions are considering as a means of improving the quality of building system and, at the same time, as the sustainable development of the city. It is configured so as a means of solving problems, not only for the scale of building technology, but also for the environmental, economic, social and employment problems (2).

In Liguria, one of the Italian Regions, the Municipalities of the small, medium and large towns are homeowner of some thousands of buildings.. Almost the $90 \%$ of them are for residential use, they were mainly built between the late '20s and early '90s. Most of these buildings was built before the first Italian legislation on the reduction of energy consumption in the residential and commercial sector (Law 373/76). Therefore often it is found a low efficient building envelope and heating system.

Genoa (with other thirty European cities) is one of "Smartcity" that it shall receive funding (nearly 11 billion over 10 years) by the European Community (Figure. 1). In the 2011 Genoa was winner of three different projects for the "Smart Cities and Communities, 2011" European call, launched by the European Commission (Seventh Framework Program), one of which is the object of the present work, R2CITIES (the other two names are "Trasnsform" and "Celsius") (3-4).

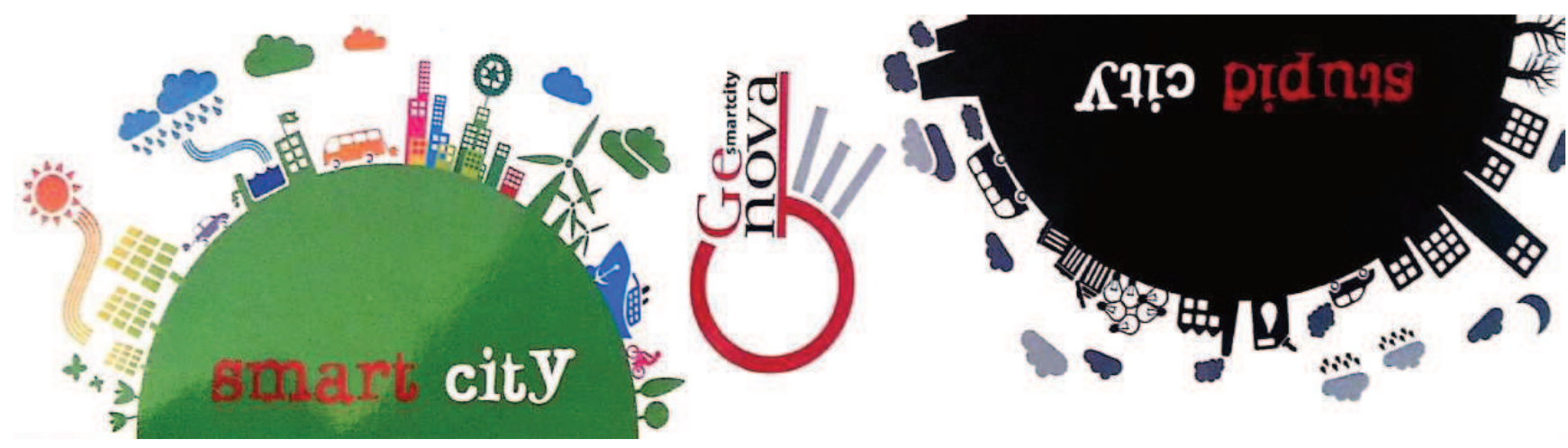

Figure 1. Smartcity in Genoa: the logo.

\section{R2CITIES: the pilot retrofitting project for an Italian social housing district}

The R2CITIES mainly aims to develop and demonstrate an open and easily replicable strategy for designing, constructing, and managing large scale district renovation projects for achieving nearly zero 
energy cities. For this purpose, it will be developed a demonstration and dissemination framework of innovative strategies and solutions for building energy renovation at district level. Three demo sites will be addressed for demonstrating the framework and associated impacts by developing real cases going beyond current market standards but ensuring the replicability of the concepts deployed. Valladolid, Genoa and Kartal (Istanbul) Municipalities will provide three demo sites for a "ambitious renovation" of three residential districts. For Genoa was chosen a part of the Pegli 3 district, a district in the west part of Genoa, the "Wash Machines" buildings. The Italian partnership is composed by Municipality, researchers, industries, no-profit companies and financial companies.

The "Wash Mascines" are large residential buildings within the large project of public working-class neighborhood located in Pegli 3, a peripheral hill of Genoa (Figure. 2). The original Zone Urban Plane (PDZ) of Pegli 3 (by application of the Italian Law for council housings 167/62, 1976) includes many hectares with a capacity of many thousands of habitants. It is divided into several sectors where a lot of social services were included (i.e. schools, spaces for sports, supermarkets, highways, etc). Only some sectors were built with public and private investments. One of the sectors is characterized by the presence of the "Wash Machines" (the subject of this work, le Lavatrici). Their names are due to the presence of many circular portholes on the façades; they are built on an hill following the morphology. The project is characterized by the simultaneous presence of social housing and private housing. In particular the site consists of more than 600 dwellings. It is divided in four main blocks and each of them is composed by three different buildings: a high block, a lower block, and a centre clock of apartments that span a large change in elevation called "the steps". The complex is diverse in ownership (some public some private), energy infrastructure (some renovated some not), and population (some private, some public, young, and old). The complex has one common area, ample parking, and is served by a public bus line.

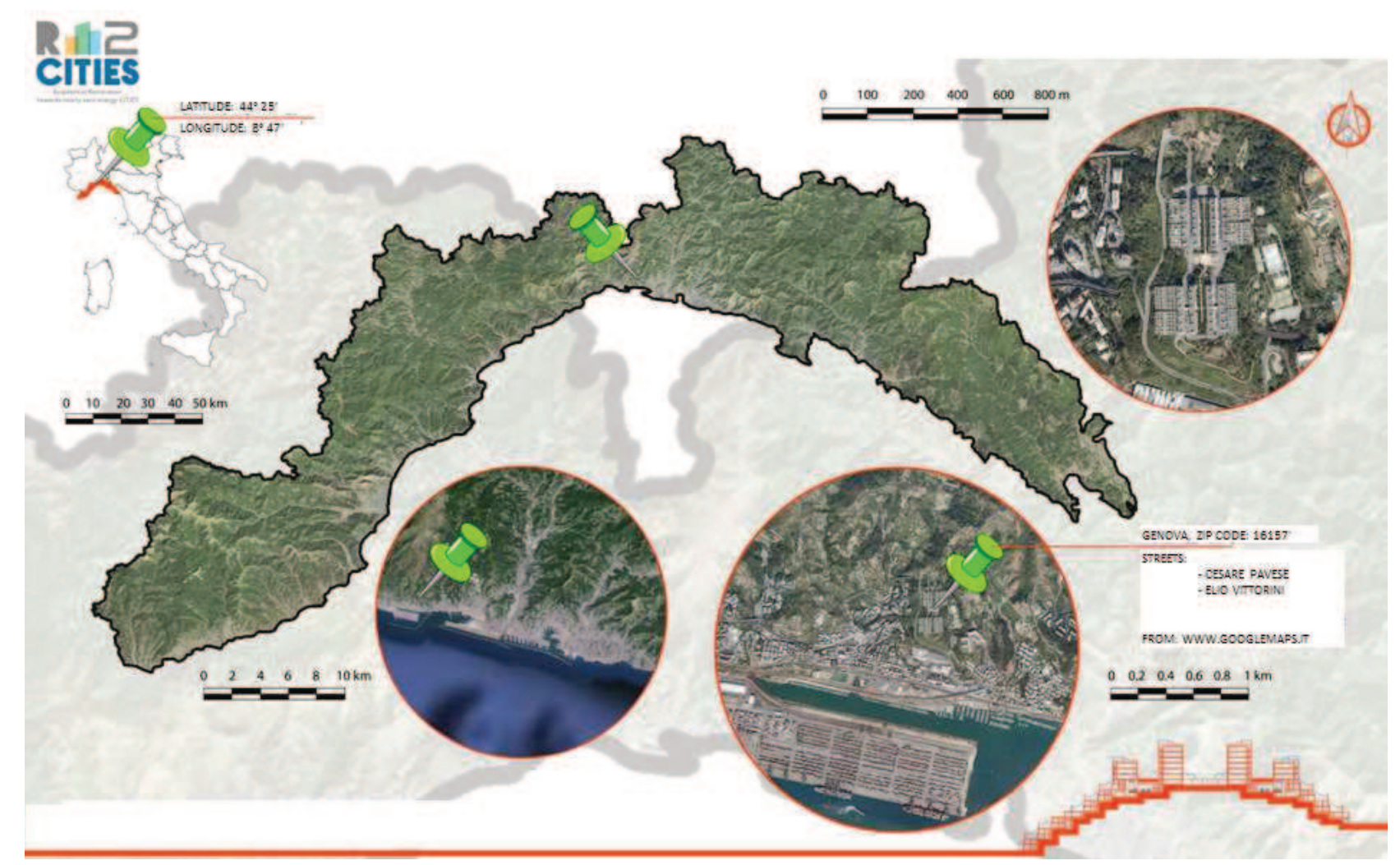

Figure 2. The Pegli 3 district: localization of "Wash Machines". 
The housing district brings itself considerable energy and the environment critical states, due to the large size and the public character of the buildings. For these reasons the requalification of the construction is considered a tool to reduce the very high costs for management that could help to elevate the level of social and environmental sustainability of entire neighborhoods.

The Wash Machines were built from the 1983 and the 1989. It was used the banches et tables constructive technique. The main technical data of buildings are (Figure. 3-4):

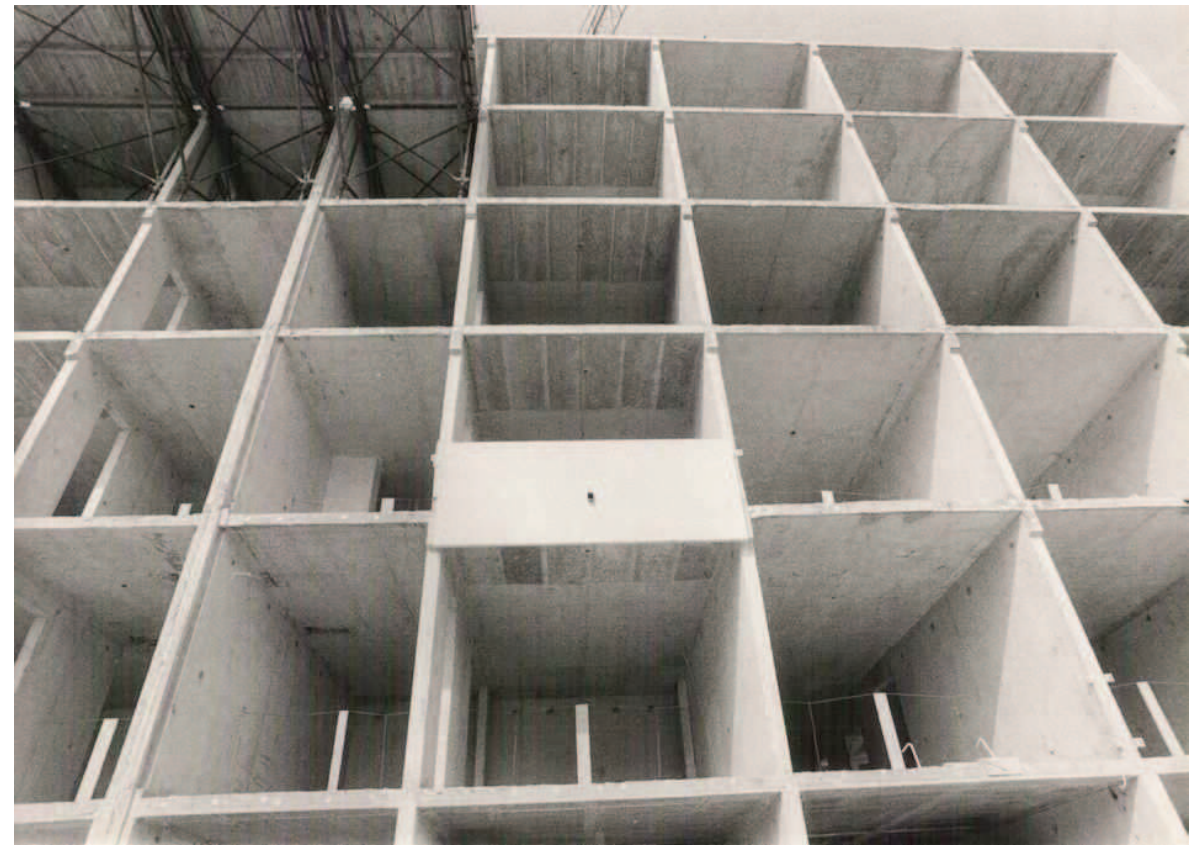

Figure 3. The Wash Mashines: the banches et tables French constructive technique.

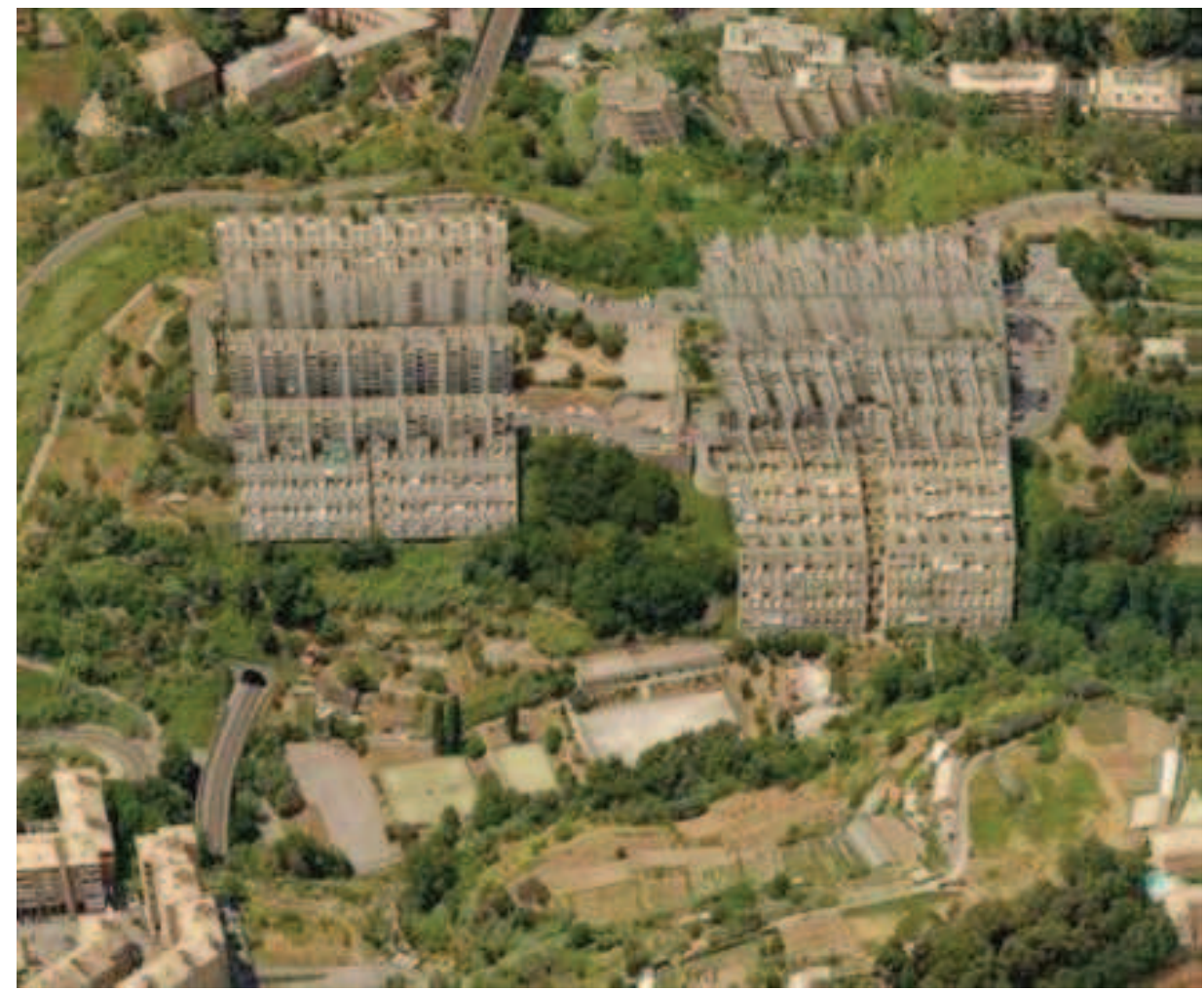

Figure 4. Bird's-eye view: West view. 
- Type of structure: cast reinforced concrete (depth horizontal and vertical sets: $0.15,0.20,0.25 \mathrm{~m}$ )

- Typology of dwellings: simplex floor with balcony (face oriented to East or West), simplex floor with double faces (faces oriented to East/West), duplex floors (faces oriented to East or West).

- Typology of common spaces: several different shape spaces for common activities; independent (structurally and for distribution) elevators and staircases for every condominium.

- Main characteristics of constructive elements: foundation on pilots or continue, flat roof, façade with precast wall panels filled with thermal insulation foam and lightweight concrete blocks, windows with metal frame and double air glazing, South and Nord Façades without windows (Fig. 5).
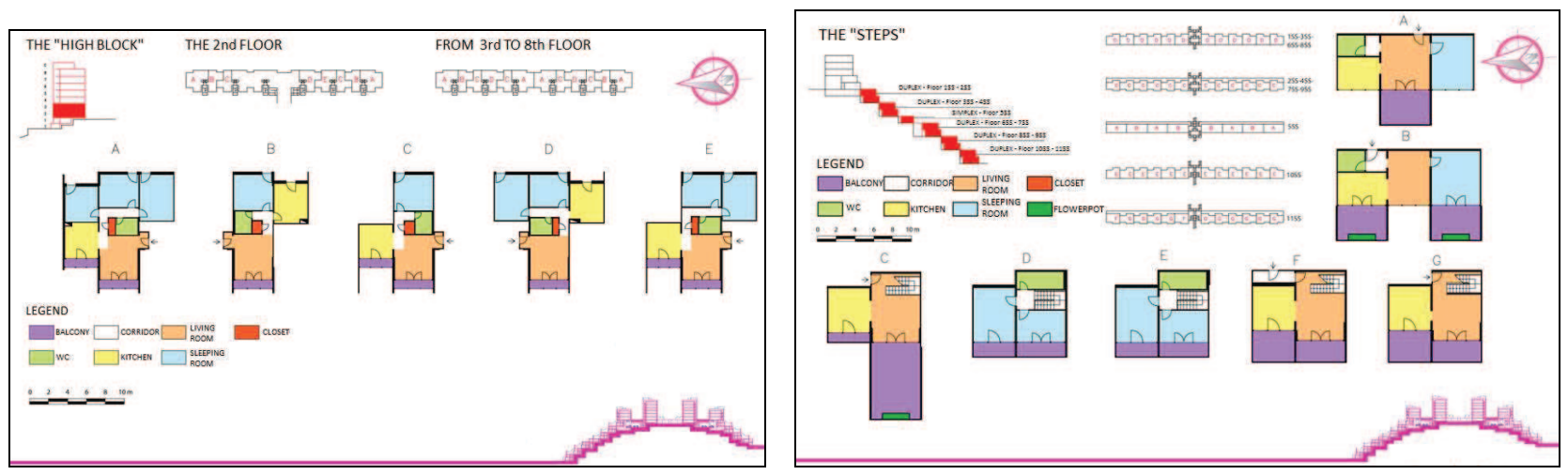

Figure 5. Representative plaint of Wash Machines.

\section{Technical details of the requalification project}

The requalification project concerns only a part of the Wash Machines buildings, because the European Commission has granted restoration of not more than $18000 \mathrm{~m}^{2}$. Therefore a portion of the building is identified (Figure. 6), that encloses all types of construction and housing of the buildings.

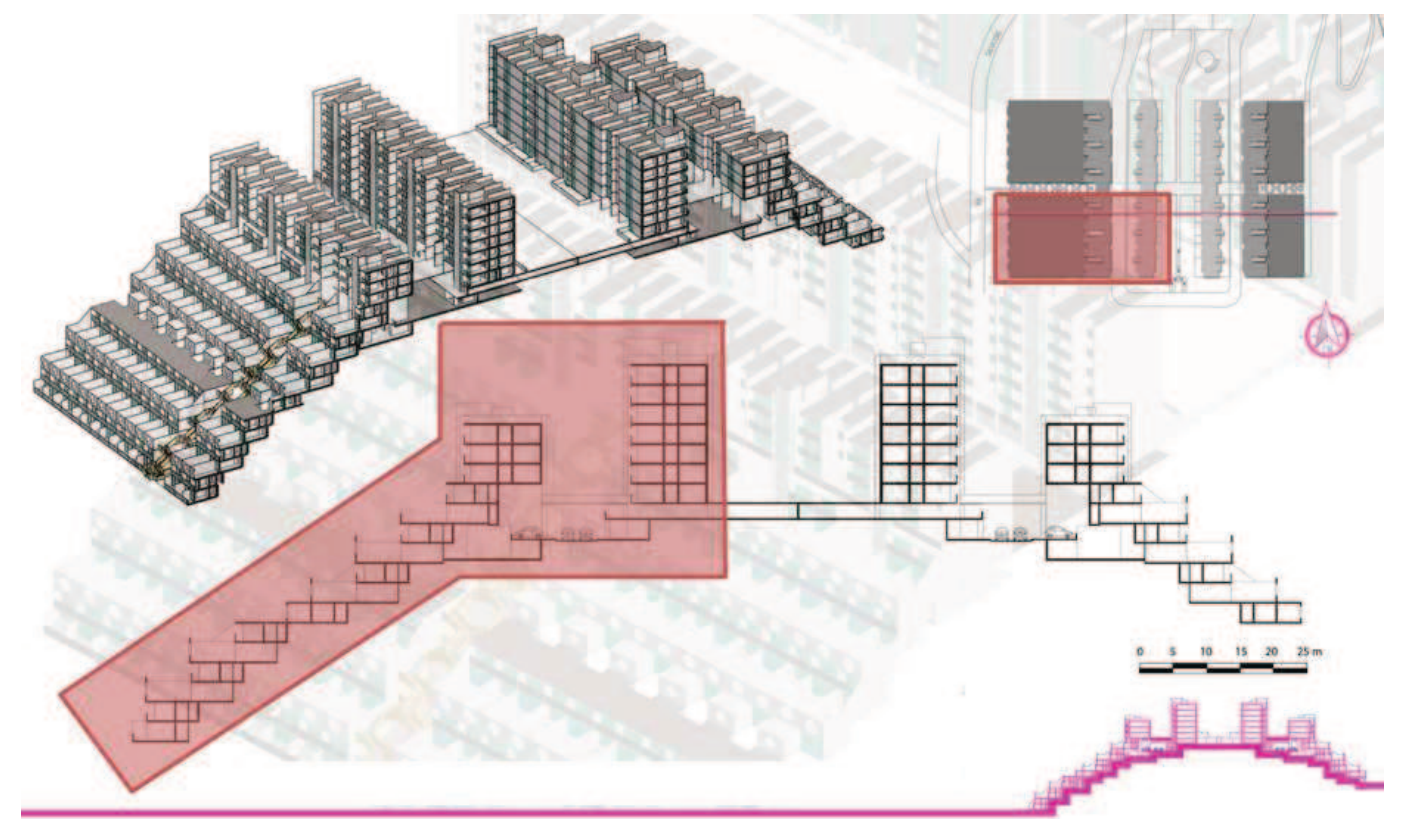

Figure 6. The requalification zones of Wash Machines. 
The main objective of the project is to identify operative solutions with the following common factors: reducing energy consumption by at least $50 \%$; increasing sustainable properties in terms of reduced production of greenhouse gases; increasing internal comfort conditions through passive solutions; use of innovative technologies with low economic impact; normalization of the solutions adopted for a real replication in other "parts" of the district and, in general, in other requalification projects.

For the requalification project "standard" and defined "morphological" solutions, that take advantage of the peculiar characteristics of buildings, are chosen. Some solutions considering the total 18000 $\mathrm{m}^{2}$, other, decidedly experimental, will be executed in a "in situ laboratory", including two dwellings, located at an intermediate level and representing a high percentage of housing units of Wash Machines (Figure. 6).

The project intend to improve the sustainability performance of the building with technical solutions applied to the external envelope. The following solutions are designed (5-8):

- Standard solutions with traditional and innovative techniques:

+ Thermal insulation (in the $18000 \mathrm{~m}^{2}$ and in the "in situ laboratory")

+ Thermal bridges elimination (in the $18000 \mathrm{~m}^{2}$ and in the "in situ laboratory")

+ Change of external windows (in the $18000 \mathrm{~m}^{2}$ and in the "in situ laboratory")

- Morphological solutions (with automation system for thermal, hygrometric, lighting and security control):

+ Transformation of common area in "common greenhouse" (in the $18.000 \mathrm{~m}^{2}$ )

+ Installation of hybrid photovoltaic panels with storage (on the roof and in the South façades)

+ Transformation of balcony in greenhouse (in the $18000 \mathrm{~m}^{2}$ and in the "in situ laboratory" with automation system for thermal, hygrometric, lighting and security control)

+ Transformation of the windows in "solar high thermal and lighting performance windows (in the "in situ laboratory").

\subsection{Preliminary performances analyses}

The performances of current state of maintenance and requalification project are carried out as preliminary analyzes (for the winter/summer regime and according to current Italian regulations) in terms of: a) temperature and humidity performances of individual building elements, b) energy needs of $18000 \mathrm{~m}^{2}$ and of the "laboratory", c) winter energy class, d) sustainable properties through life cycle analyses (LCA).

The preliminary energy performances results considers only the "standard" solutions, because the quantitative assessments of the "morphological" solutions require complex numerical analyses that will 
be performed during the next development phases of the European project. These first results are nevertheless encouraging because they show an overall reduction in winter energy requirements higher than $50 \%$, a summer energy requirements reduction exceeding the $45 \%$ and a change of winter energy class from the "E" class to the "A or B" class (considering the energy classes of the Regional Law of Liguria, Italy n. 6/2012). Furthermore it should be noted that a detailed analysis of individual "standard" solutions highlights the different influences on the energy savings of insulating paintings, artificial fiber insulation panels and replacement of high performances windows.

The application of the LCA to the requalification project has as main purpose the evaluation of sustainable advantages of the project in comparison with the current state of maintenance. Second it wants to be a verification tool for the optimal choice of materials and construction elements.

\section{Acknowledgments}

Financial support for this study was provided by a grant from the European Commission (Smart Cities and Communities 2011, FP7). The author wish to thank Dot. C. Vite and M. Vassale for their work in researching about requalification and LCA application on "Wash Machines" buildings.

\section{Conflict of Interest}

State any potential conflicts of interest here or "The authors declare no conflict of interest".

\section{References and Notes}

1. Amato, A. L'ulivo sul tetto, 1892-1992: cent'anni di edilizia genovese fra storia e ricordo, Casa Edile Genovese, Genova, Italy, 1992;

2. Bobbio, R. Un secolo di storia al servizio dell'edilizia sociale, A.R.T.E., Genova, Italy, 2009;

3. AA.VV. S.E.A.P Sustainable Energy Action Plan, Municipality of Genova, Genova, Italy, 2010;

4. AA.VV. L'innovazione energetica in edilizia, Cresme Ricerche Spa, Legambiente, ONRE, 2013;

5. Szokolay S. V. Introduction to Architectural Science: The Basis of Sustainable Design, Elsevier/Architectural Press, U.K., 2008;

6. Givoni B. Climate considerations in Building and Urban Design, Int. Thomson Publishing, London, U.K., 1998;

7. Givoni B.. Man, Climate and Architecture, Applied Science Pubblisher, London, U.K., 1969;

8. Olgyay V. Design with Climate, Cresme Princeton University Press, New Jersey, USA, 1963. 